\title{
O descuido com a taxonomia pode desvalorizar um trabalho científico
}

\author{
Disregard for taxonomy can devalue a scientific paper
}

Senhor Editor:

A correta identificação dos insetos na realização de um trabalho científico é fundamental para se avaliar a susceptibilidade a parasitas, a sensibilidade a substâncias tóxicas, a biologia e a eventual importância epidemiológica. Para isso, são realizados estudos taxonômicos detalhados, demorados e complexos.

Após a publicação destes estudos taxonômicos, não é racional a insistência em desconsiderar a distinção taxonômica, para não correr o risco de desvalorizar os seus próprios resultados. Desde que seja viável a identificação dos insetos estudados, se eles não forem adequadamente distribuídos dentro dos grupos conhecidos e se não for publicada a sua distribuição nestes grupos, serão perdidas, sem necessidade, informações muito importantes.

Os flebotomíneos antes incluídos em Lutzomyia intermedia (Lutz \& Neiva, 1912) podem ser agrupados em duas espécies [L. intermedia s. S. e L. neivai (Pinto, 1926)], que constituem um complexo de espécies ${ }^{3}$. A identificação das fêmeas é facilmente feita pela observação das espermatecas e de seus dutos e dos dentes do cibário, além de existirem várias diferenças morfométricas adicionais ${ }^{7}$. Os machos podem ser diferenciados por morfometria, utilizando proporções entre medidas de estruturas e análise por rede neural ${ }^{4}$. O estudo do DNA mitocondrial permitiu distinguir dez haplótipos, alguns característicos de cada espécie, e ressaltou a proximidade entre as espécies ${ }^{5}$.

As duas espécies apresentam distribuição geográfica distinta e precisam ser estabelecidos os limites exatos entre as distribuições de ambas e as áreas em que elas são simpátricas ${ }^{8}$. A L . intermedia parece ocorrer em áreas mais quentes e úmidas que a $L$. neivai e ambas ocorrem no Vale do Ribeira, no sul do Estado de São Paulo, o que torna especialmente importante a identificação cuidadosa de material desta região. Foram revisadas todas as referências anteriores a L. intermedia, Phlebotomus intermedius e outros ${ }^{6}$, de modo a organizar os dados referentes a estes insetos.

Flebotomíneos deste complexo têm sido incriminados na transmissão de parasitas de Leishmania ${ }^{129101112}$. O estudo de infecção experimental destes insetos ${ }^{9}$ é muito importante e precisa ser ampliado, se possível obtendo a transmissão entre mamíferos.

Assim, a infecção experimental de flebotomíneos referidos como de $L$. intermedia, de campo e de laboratório ${ }^{13}$ veio contribuir para o esclarecimento desta questão. No entanto, este trabalho, em que foram estudados numerosos insetos do Vale do Ribeira, não faz referência a qualquer dos estudos taxonômicos supracitados, o que deixa o leitor com duas hipóteses, ou seja, que os autores consideram o aspecto taxonômico irrelevante para o seu trabalho ou que não concordam com a distinção entre as espécies. Se os insetos fossem provenientes de alguma área na qual só tivessem sido encontrados exemplares de uma das espécies do complexo, como o Estado do Rio de Janeiro ${ }^{1011}$, a Argentina ${ }^{12}$ ou o interior de São Paulo², seria bastante seguro, com os dados disponíveis, deduzir a qual espécie pertenciam os insetos estudados, mesmo não tendo sido ela devidamente citada. No entanto, por serem os insetos do estudo supracitado ${ }^{13}$ de uma área em que ambas as espécies ocorrem ${ }^{34678}$, só é possível concluir que os insetos pertencem a L. intermedia s. I. Como o trabalho refere-se aos insetos de um estudo do interior de São Paulo ${ }^{2}$ como L. intermedia, apesar de todos os exemplares estudados de insetos desta região terem sido identificados como

Departamento de Microbiologia e Parasitologia do Centro de Ciências Biológicas da Universidade Federal de Santa Catarina, Campus Trindade, Florianópolis, SC. Address to: Dr. Carlos Brisola Marcondes. Depto de Microbiologia e Parasitologia/UFSC, Campus Trindade, 88040-900 Florianópolis, SC. Fax: 55483319672

e-mail:cbrisola@mbox1.ufsc.br.

Recebido para publicação em 25/6/2001. 
L. neiva $\beta^{3678}$, permanecem as hipóteses supracitadas sobre as razões dos autores para a não diferenciação.

A não ser que seja comprovado (e publicado) no futuro que a distinção entre as duas espécies do complexo não é válida e que os grupos não têm valor taxonômico e biológico algum, o trabalho supracitado ${ }^{13}$ corre grande risco de desperdiçar informação. Quando este for lido, ficará sempre a dúvida de a que espécie pertenciam os insetos estudados.

Deste modo, para impedir que pairem quaisquer dúvidas e valorizar o trabalho, é fundamental que os autores, se tiverem feito a distinção, no momento da dissecção dos insetos para exame de infecção, esclareçam qual era a espécie a que pertenciam. Se os autores não concordarem com a distinção entre as duas espécies ou considerarem que ela não tem base científica suficiente, é preciso que explicitem isto no futuro, após cuidadoso estudo taxonômico, mas que, de qualquer modo, divulguem quais as quantidades de insetos que têm as características referidas como úteis para a distinção específica ${ }^{37}$. O que não é admissível, em trabalhos que envolvam insetos do complexo L. intermedia, é que seja usada nomenclatura antiga e excessivamente abrangente, sem nenhuma justificativa expressa ou contestação publicada à distinção entre as espécies.

Do mesmo modo, é conveniente que revistas especializadas em medicina tropical e similares tenham mais cuidado na avaliação de estudos que envolvam taxonomia, exigindo nestes o máximo cuidado na identificação do material, para valorizar os trabalhos que publica. Numa época em que os índices de citação (e.g., ISI) tornam-se a cada dia mais importantes, este cuidado é fundamental para os autores dos trabalhos e para as revistas.

\section{Carlos Brisola Marcondes}

\section{REFERENCIAS BIBLIOGRÁFICAS}

1. Deane LM, Grimaldi Jr G. Leishmaniasis in Brazil. In: Chang JP, Bray RS (eds) Leishmaniasis. Elsevier Sci Publ, Amsterdam, p. 247-281, 1985.

2. Forattini OP, Pattoli DBG, Rabello EX, Ferreira AO. Infecção natural de flebotomíneos em foco enzoótico de leishmaniose tegumentar no Estado de São Paulo. Revista de Saúde Pública 6:431-433, 1972.

3. Marcondes CB. A redescription of Lutzomyia (Nyssomyia) intermedia (Lutz \& Neiva, 1912), and resurrection of L. neivai (Pinto, 1926) (Diptera, Psychodidae, Phlebotominae). Memórias do Instituto Oswaldo Cruz 91:457-462, 1996.

4. Marcondes CB, Borges PSS. Distinction of males of Lutzomyia intermedia (Lutz \& Neiva, 1912) complex by ratios between dimensions and by an Artificial Neural Network (Diptera, Psychodidae, Phlebotominae). Memórias do Instituto Oswaldo Cruz 95:685-688, 2000.

5. Marcondes CB, Day JR, Ready PD. Introgression between Lutzomyia intermedia and both Lu neivai and Lu whitmani, and their roles as vectors of Leishmania braziliensis. Transactions of the Royal Society of Tropical Medicine and Hygiene 91:725-726, 1997.

6. Marcondes CB, Lozovei AL. Records revision of Lutzomyia intermedia (Lutz \& Neiva, 1912) complex (Diptera, Psychodidae, Phlebotominae). Iheringia 87:157-170, 1999.

7. Marcondes CB, Lozovei AL, Galati EAB, Taniguchi HH. The usefulness of Bergmann's rule to the distinction of members of Lutzomyia intermedia species complex (Diptera, Psychodidae,
Phlebotominae). Memórias do Instituto Oswaldo Cruz 93:363364, 1998.

8. Marcondes CB, Lozovei AL, Vilela JH. Distribuição geográfica de flebotomíneos do complexo Lutzomyia intermedia (Lutz \& Neiva, 1912). Revista da Sociedade Brasileira de Medicina Tropical 31:51-58, 1998.

9. Rangel EF, Barbosa AF, Andrade CA, Souza NA, Wermelinger ED. Development of Leishmania (Viannia) braziliensis Vianna, 1911 in Lutzomyia intermedia (Lutz \& Neiva, 1912) (Diptera: Psychodidae: Phlebotominae) under experimental conditions. Memórias do Instituto Oswaldo Cruz 87:235-238, 1992.

10. Rangel EF, Souza NA, Wermelinger ED, Barbosa AF. Infecção natural de Lutzomyia intermedia Lutz \& Neiva, 1912, em área endêmica de leishmaniose tegumentar no Estado do Rio de Janeiro. Memórias do Instituto Oswaldo Cruz 79:395-396, 1984.

11. Rangel EF, Souza NA, Wermelinger ED, Barbosa AF. Infecção natural de Lutzomyia intermedia Lutz \& Neiva, 1912, em área endêmica de leishmaniose tegumentar no Estado do Rio de Janeiro. Memórias do Instituto Oswaldo Cruz 79:395-396, 1984.

12. Romaña C, Abalos J. Distribución de Flebotomos y leishmaniasis tegumentaria en la Argentina. Anales del Instituto de Medicina Regional 2:293-302, 1949.

13. Silva AC, Gomes AC. Estudo da competência vetorial de Lutzomyia intermedia (Lutz \& Neiva, 1912) para Leishmania (Viannia) braziliensis Vianna, 1911. Revista da Sociedade Brasileira de Medicina Tropical 34:187-191, 2001. 